\title{
Atividades experimentais de demonstração no ensino de ciências nos anos iniciais: contribuições para uma formação crítica na educação em ciências
}

\section{Experimental activities of demonstration in the teaching of sciences in the initial years: contributions to a critical formation in science education}

\author{
${ }^{1}$ Marcelo Souza Paula magaldri@gmail.com
}

\begin{abstract}
RESUMO
O presente artigo trata-se de uma pesquisa bibliográfica e qualitativa no qual visa discutir a importância do uso de atividades experimentais de demonstração em sala de aula para a construção dos conceitos científicos dos estudantes. Destaca as contribuições dessas atividades para a formação científica em educação em ciências, proporcionando a capacidade de Tomada de Decisões na sociedade em que esses estudantes estão inseridos, principalmente no tocante à relação com os fenômenos da natureza. Discute a relação dessas atividades com a capacidade potencial em desenvolver uma aprendizagem significativa. Apresenta importantes abordagens acerca do estudo Vygotsky para esse campo de discussão, em especial a interface do uso dessas atividades com o desenvolvimento da capacidade de trabalho em grupo, fortalecendo o processo de interação social. Este estudo intensifica ainda a discussão no que tange a importância desse recurso como caminho eficaz para o fortalecimento do processo de alfabetização científica dos estudantes.
\end{abstract}

Palavras-chave: Atividades Experimentais. Alfabetização Científica. Aprendizagem Significativa.

\begin{abstract}
The present article deals with a bibliographical and qualitative research in which it aims to discuss the importance of the use of experimental activities of demonstration in the classroom for the construction of the scientific concepts of the students. It emphasizes the contributions of these activities to the scientific formation in science education, providing the capacity of Decision Making in the society in which these students are inserted, mainly in relation to the relation with the phenomena of nature. It discusses the relationship of these activities with the potential capacity to develop meaningful learning. It presents important approaches about the Vygotsky study for this field of discussion, especially the interface of the use of these activities with the development of the capacity of work in group, strengthening the process of social interaction. This study further intensifies the discussion regarding the importance of this resource as an effective way to strengthen the students' scientific literacy process.
\end{abstract}

Keyword: Experimental Activities. Scientific Literacy. Significant Learning.

1 Universidade Federal do Estado do Rio de Janeiro - UNIRIO 


\section{INTRODUÇÃO}

Somente a partir da década de 30, com a influência do movimento renovador da Escola Nova e do Manifesto dos Pioneiros que o currículo de Ciências começou a ser incorporado ao ensino brasileiro. Tal fato trouxe uma necessidade na reestruturação no currículo das escolas brasileiras, visando redefinir o ensino, os espaços e as relações escolares. Verifica-se, sobretudo, que o ensino de ciências passa a ser obrigatório nas escolas públicas, em todos os níveis, tardiamente.

Atualmente a Educação em Ciências no Brasil tem sido marcada por um processo lento e deficitário, trazendo consigo certo distanciamento entre a construção do conhecimento científico e sua aplicabilidade nas situações-problemas do cotidiano dos estudantes.

Embora expressada com nítido avanço, dados mostram que o Brasil ocupa posições desfavoráveis no que se refere à avaliação do conhecimento científico. Países com dimensões geográficas e econômicas inferiores ao Brasil, inclusive no que se refere ao PIB, apresentam resultados mais satisfatórios nas avaliações internacionais. Neste contexto, considerando a América do Sul é possível encontrar países com resultados superiores ao Brasil, como por exemplo, Chile e Uruguai.

O Programa Internacional de Avaliação de Alunos - PISA ( Programme for International Student Assessment)/2012 revela que o Brasil, no que se refere ao conhecimento em ciências, apresentou pequeno avanço em relação às últimas avaliações, entretanto, ocupando a 59a posição em relação aos demais países, num total de 65 países. Distante dos países no topo da lista, os asiáticos, este programa tem como objetivo medir o conhecimento e a habilidade em leitura, matemática e ciências de estudantes com 15 anos de idade, tanto de países membros da OCDE (Organização para a Cooperação e Desenvolvimento Econômico) como de países parceiros.

Com pontuação alcançada somente em nível I de conhecimento, os estudantes brasileiros pouco são capazes de aplicar o que sabem em diferentes situações de seu cotidiano, bem como dar explicações científicas para determinados fenômenos da natureza.

O reflexo deste resultado pode ser ratificado quando comparado com avaliações externas das escolas públicas brasileiras realizadas pelo Ministério da Educação - MEC. O Índice de Desenvolvimento da Educação - IDEB, indicador cujo objetivo é verificar como as políticas públicas instituídas pelo Ministério, por meio do Compromisso "todos pela educação" têm proporcionado melhorias nessas escolas, em especial na aprendizagem dos estudantes.

Diante do quadro exposto, percebe-se que os conhecimentos científicos dos alunos não são suficientes para dar explicações a determinadas situações do seu cotidiano, em especial na relação aos fenômenos da natureza, ou de situações mais complexas. Este fato demonstra que a aprendizagem não tem se configurado como significativa para os estudantes.

Instituída como uma tentativa para minimizar essa problemática e conceber as contribuições da tecnologia na construção do conhecimento científico, a tendência pedagógica Ciência/Tecnologia/Sociedade - CTS (atual CTSA) apresentada nos Parâmetros Curriculares Nacionais para o Ensino de Ciências chega às escolas brasileiras se configurando como um momento ímpar para a relação entre a ciência e a escola e, em especial, a sociedade.

Cabe ressaltar, o importante desafio do Brasil para reversão desse quadro, pautado numa política que vise à popularização do conhecimento nas escolas públicas e trabalhando para que o processo de alfabetização científica se configure como uma política permanente nos projetos pedagógicos escolares, sendo propagado em toda comunidade, não somente intra, mas também extra-escolar. 


\title{
2 A IMPORTÂNCIA DO PROCESSO DE ALFABETIZAÇÃO CIENTÍFICA PARA O ENSINO DE CIÊNCIAS.
}

Atualmente o Ensino de Ciências no Brasil tem apresentado um quadro histórico de estudantes que chegam ao Ensino Médio e, até mesmo no Ensino Superior de posse de um empobrecimento na fundamentação teórica da sua Educação Científica. Na sociedade em que vivem, esses estudantes trazem consigo uma dificuldade para explicar e relacionar-se com determinados fenômenos da natureza.

Entender que a relação dos conhecimentos em ciência está estritamente ligada com sua prática cotidiana, e, sobretudo, com uma alfabetização científica democrática e libertadora, no estado da sua formação cidadã, tem se configurado como caminho eficaz para o processo de tomada de decisões desses estudantes.

Considerando esses aspectos, torna-se inconsistente pensar em um ensino de Ciências do modo como ele se apresenta atualmente, estagnado em um ensino obsoleto e pouco significativo aos alunos. "A formação científica que requer atualmente o desempenho cidadão não é a formação tradicional” (TEDESCO, 2009, p. 165).

Corroborando com essa linha de discussão, Pessoa de Carvalho (2009) nos atenta para que,

Não basta e na verdade temos dados empíricos mostrando que não adianta o ensino se reduzir a uma coleção de fatos, conceitos, leis e teorias como tradicionalmente são apresentados aos alunos, pois dessa maneira, no melhor dos casos, o que realmente permanece com eles, no final da escola média, é uma visão reducionista do que seja produção de conhecimento pela humanidade. (PESSOA DE CARVALHO, 2009, p. 72)

A partir dessa premissa, vale ressaltar que o ensino de ciências necessita ir além dos aspectos meramente informativos, dos quais os formativos precisam sobrepor:

\begin{abstract}
E mais importante, ao invés de simplesmente buscarmos transmitir os conhecimentos aos alunos, “[...] levar os alunos a produzirem conhecimento significativo não só sobre o conteúdo das disciplinas científicas como também, e principalmente, sobre o processo da construção da própria ciência” (PESSOA DE CARVALHO, 2009, p. 72-73).
\end{abstract}

Nota-se, sobretudo, que o ensino de ciências precisa romper essas barreiras e preocupar-se com um ensino pautado na formação crítica dos cidadãos, entendendo que a educação científica deve preocupar-se com uma formação que vise melhorar a sua relação com a sociedade em que vive. Ademais, Todas as pessoas deveriam ter certa compreensão dos processos e da natureza do conhecimento científico: “[...] a nação que não der atenção à educação científica de sua população estará comprometendo seu desenvolvimento e o futuro da sociedade" (AMABIS, 2009, p. 156). Pavan (2009, p. 103) complementa informando que "sem investimentos na área o retrocesso social será inevitável”.

No tocante ao campo da discussão acerca do processo de alfabetização científica dos estudantes, configura-se importante instituir uma política que valorize sua democratização no espaço formal de ensino, pois sob um aspecto contrário, acarretará certo distanciamento com a sua prática cotidiana, propiciando assim, uma alienação na sociedade em que vive. Druck (2009) ratifica que essa suposta alienação de parte da população quanto ao conhecimento científico chega até mesmo a causar sua exclusão.

Informações sobre saúde, alimentação, cálculos de impostos, gráficos de distribuição de renda, a incrível velocidade com que se divulgam informações pela internet, e muitos outros benefícios espetaculares do conhecimento científico, estão indisponíveis para as massas da população brasileira que incapazes de entendê-los e usá-los adequadamente, permanecem à margem do progresso científico (DRUCK, 2009, p. 234). 
A escola, a qual se intitula plural, deve, sobretudo, conceber seu espaço como importante veículo no tratamento desse contexto, pois o que se leva a cabo é o direito de igualdade de informações, que nesse caso, deve ser o caminho para uma formação cientifica cidadã, para todos. Por meio desse aspecto, Bourdieu (2006) ressalta:

Com efeito, para que sejam favorecidos os mais favorecidos e desfavorecidos os mais desfavorecidos, é necessário e suficiente que a escola ignore, no âmbito dos conteúdos do ensino que transmite, dos métodos e técnicas de transmissão e dos critérios de avaliação, as desigualdades culturais entre as crianças das diferentes classes sociais. Em outras palavras, tratando todos dos educandos, por mais desiguais que sejam eles de fato, como iguais em direitos e deveres, o sistema escolar é levado a dar sua sanção às desigualdades iniciais diante da cultura. (BOURDIEU, 2006, p 53)

No intuito de corroborar com essa discussão, Krasilchik (2009) sustenta ainda a idéia de que "a escola brasileira atual é uma instituição cujo objetivo maior deve ser a inclusão social do cidadão, eliminando diferenças que excluam os menos privilegiados”.

Neste ínterim, a educação científica aqui desejada deve ser de cunho eminentemnte democrática, sendo concebida ao maior número possível de cidadãos e camdas sociais. Sobretudo, ainda estabelecer uma interface com os aspectos tencológicos, no intuito de fortalecer os processos de interesse da população científica e sua relação com a sociedade.

Continuar aceitando que grande parte da população não receba formação científica e tecnológica de qualidade agravará as desigualdades do país e signficará seu atraso no mundo globalizado. Investir para construir uma população cinetificamente é cultivar para receber de volta a cidadania e a produtividade que melhoram as condições de vida de todo o povo (WERTHEIN \& CUNHA, 2009, p.15).

Cabe ressaltar que um cidadão alfabetizado cientificamente utiliza de seus conhecimentos para realizar tomadas de decisões na sociedade em que vive, tanto nos aspectos sociais, culturais, quanto nos aspectos tecnocientíficos.

À luz do contexto supramencionado, um campo que traz importantes considerações é o da Ciência/Tecnologia/Sociedade, denominada por alguns pesquisadores por CTS. Segundo Valério e Bazzo (2006) são feitas as seguintes observações sobre CTS:

A divulgação científica, tal qual é pensada e praticada atualmente, congrega uma série de questões problemáticas, dentre as quais, a maneira como concebe e contempla as inovações em C\&T. Até o presente momento a maior parte dos veículos de divulgação científica tem se preocupado pouco com a sua dimensão educativa e, assim, não contribuem significativamente com a formação em seu público de uma visão crítica sobre C\&T. Em geral, são poucas as iniciativas que tem considerado este potencial da divulgação e, infelizmente, esta tarefa tem ficado a cargo daquelas que possuem menor inserção social, como os museus interativos de ciência, por exemplo. Já em outros instrumentos de comunicação social de massa, como é o caso da televisão, o que se tem é uma noção bastante simplificada da prática científica/tecnológica. Na maioria dos casos, os temas em C\&T são tratados de maneira bastante descontextualizada e pouco reflexiva, fazendo perdurar a ultrapassada concepção de superestima e otimismo cego na C\&T. (VALÉRIO \& BAZZO, 2006, p. 6-7).

Desta forma, considerando essa linha teórica de pensamento, cabe destacar a importância da escola instituir uma política, assim como estratégias pedagógicas motivadoras, no sentido de inserir os estudantes num processo de (re)construção de uma ciência crítica-reflexiva e, paralelamente, da sua cultura científica e tecnológica, conforme ressaltam PRAIA; GIL-PÉREZ; VILCHES (2007):

Pretende-se, assim, fomentar a alfabetização científica e tecnológica dos cidadãos por intermédio de uma certa imersão na cultura científica e tencológia, fundamental para a formação de cidadãos e cidadãs críticos que, no futuro, participarão na tomada de decisões (PRAIA et al., 2007, p. 152). 
Conforme corroboram os autores acima, a cultura científica dos estudantes é ponto fundamental para a sua formação crítica no ensino de ciências, todavia, deverá transformar-se num ato de transformação social e relação dentro do processo de alfabetização científica.

\section{USO DE ATIVIDADES EXPERIMENTAIS DE DEMONSTRAÇÕES NO ENSINO DE CIÊNCIAS. CAMINHO PARA UMA APRENDIZAGEM SIGNIFICATIVA}

No campo das discussões acerca da realização de atividades experimentais pelos professores como processos práticos, formativos e democráticos, ressaltam-se os desafios que revelam contribuições eficazes para uma aprendizagem realmente significativa, Santos (2008, p.63), destaca que "o papel do professor diante da necessidade de promover uma aprendizagem significativa é de desconstrução de algumas atitudes, bastante enraizadas pelo paradigma cartesiano-reprodutivista”.

Segundo Laburú (2005), as atividades experimentais podem se classificadas em quatro tipos: motivacional, instrucional, funcional e epistemológica. Neste sentido, percebe-se que o papel do professor nesta prática deve ir além de simples demonstrações/ilustrações, mas que possam agregar um conjunto maior de funções e possibilitando uma aprendizagem mais fácil, agradável, menos abstrata, enfim, mais significativa.

O espaço (ou a falta de) para realização das atividades experimentais, em certos momentos, também são justificativas de determinados professores como empecilhos para a não realização desta prática. Força; Laburú e Silva (2011) apresentam a ideia de Rosito (2003) quando este se contrapõe ao relatado:

\footnotetext{
“Neste sentido, Rosito (2003, p. 206) acredita que seja possível realizar experimentos na sala de aula, ou mesmo fora dela, utilizando materiais de baixo custo, podendo contribuir para o desenvolvimento da criatividade dos alunos. Ressalta que não dispensa a importância de um laboratório bem equipado na condução de um bom ensino, mas acredita que seja possível superar a idéia de que a falta de um laboratório equipado justifique um ensino fundamentado apenas no livro didático”. (FORÇA et al., 2011, p. 3)
}

Contudo, o professor precisa ser o grande motivador e articulador de todo o processo de aprendizagem. Levar os estudantes à exposição de suas ideias, interagindo com os demais companheiros, construir coletivamente os conhecimentos se configura como estratégias que, aliadas a realização de atividades experimentais, condicionam uma educação em ciências de forma prazerosa, o que numa contraposição a essa ideia poderá causar um ensino desprovido de prazer e sede de conhecimento.

Diante dessa realidade, o desejo, a vontade, a curiosidade e a disponibilidade interna para aprender ganham especial importância. Segundo Freinet, está fadado ao fracasso, todo método que tentar fazer beber água o cavalo que não tem sede. Essa máxima nos remete à profunda reflexão sobre a importância do papel do sujeito que aprende. Mais ainda. Remete-nos à reflexão sobre o papel do professor como "provocador da sede" (SANTOS, 2008, p. 65)

À luz dessa discussão percebe-se que o processo de construção dos conceitos científicos permeia um caminho mais eficaz, de aprendizagem significativa, capaz de ser utilizado no intuito de dar respostas à determinados fenômenos da natureza e proporcionando uma melhor sustentabilidade na sociedade em que os estudantes estão inseridos.

Sobre esse aspecto cabe a seguinte reflexão: 
O modelo de aprendizagem que embasa as necessidades de nosso tempo não é mais o modelo tradicional que acredita que o aluno deve receber informações prontas e ter, como única tarefa, repeti-las na íntegra. A promoção da aprendizagem significativa se fundamenta num modelo dinâmico, no qual o aluno é levado em conta, com todos os seus saberes e interconexões mentais. A verdadeira aprendizagem se dá quando o aluno (re)constrói o conhecimento e forma conceitos sólidos sobre o mundo, o que vai possibilitar-lhe agir e reagir diante da realidade. Cremos, com convicção e com o respaldo do mundo que nos cerca, que não há mais espaço para a repetição automática, para a falta de contextualização e para a aprendizagem eu não seja significativa (SANTOS, 2008, p. 73).

Ainda sobre o prisma da aprendizagem significativa, considerando o aspecto positivo dos usos das atividades experimentais no processo de formação da educação para a ciência dos estudantes podemos compactuar com Silva e Zanon ao relatarem:

As atividades práticas podem assumir uma importância fundamental na promoção de aprendizagens significativas em ciências e, por isso, consideramos importante valorizar propostas alternativas de ensino que demonstrem essa potencialidade da experimentação: a de ajudar os alunos a aprender através do estabelecimento de inter-relações entre os saberes teóricos e práticos inerentes aos processos do conhecimento escolar em ciências. (SILVA \& ZANON, 2000, p. 134).

Cabe ressaltar ainda, que o uso de atividades experimentais no ensino fundamental aumenta a capacidade colaborativa dos estudantes, desenvolvendo o espírito de participação, coletividade e construção dos conhecimentos científicos. Desta forma, a interação social entre os estudantes propicia o desenvolvimento no que se refere aos aspectos motivacionais e da investigação, fato este de extrema relevância para a educação em ciências. Vygotsky (2001) reforça que “o que a criança é capaz de fazer hoje em colaboração, conseguirá fazer amanhã sozinha"

Inerente às contribuições de Vygotsky no uso de atividades de demonstração pode-se ressaltar o desenvolvimento de conceitos espontâneos e científicos. Sobre estes pontos nota-se que o uso das atividades experimentais possibilita essas duas abordagens, uma vez que os estudantes são desafiados à exposição dessas ideias. Deste modo, Vygotsky entende que a mente da criança se relaciona de forma diferente quando se defronta com conceitos científicos ou espontâneos.

O desenvolvimento dos conceitos espontâneos e científicos - cabe pressupor - são processos intimamente interligados, que exercem influências um sobre o outro [...] independentemente de falarmos do desenvolvimento dos conceitos espontâneos ou científicos, trata-se do desenvolvimento de um processo único de formação de conceitos, que se realiza sob diferentes condições internas e externas mas continua indiviso por sua natureza e não se constitui da luta, do conflito e do antagosnimo de duas formas de pensamento que desde o início se excluem (VYGOTSKY, 2001, p. 261).

Nesse ínterim, o uso das atividades de experimentais de demonstração em sala reforça a aproximação de diferentes saberes em uma única atividade, dentre eles os conhecimentos afins na área de ciências naturais, proporcionando uma formação científica sólida e, sobretudo, uma aprendizagem significativa.

\section{CONSIDERAÇÕES FINAIS}

Tem se tornado cada vez mais impossível pensar num ensino de ciências nos anos iniciais do Ensino Fundamental obsoleto, distante da prática da demonstração, em especial por parte dos docentes, de atividades experimentais que possibilitem a construção de conceitos científicos,/ socializados em sala.

O uso de atividades de demonstração em sala de aula tem se configurado como importante caminho para chegar a um ensino proveniente da construção coletiva dos conceitos científicos, opondo-se à prática dos conceitos trazidos pelos docentes, quando em sua prática ainda persiste um ensino tradicional. 
Conforme relatado anteriormente, o processo de alfabetização científica, o qual o espaço escolar tem papel fundamental, busca, sobretudo, tornar os estudantes capazes de tomar decisões na sociedade em que vivem. Diante deste fato, tornam-se capazes de entender e relacionar-se com os fenômenos da natureza.

Um ponto singular nesta discussão foi trazer algumas contribuições de Vygotsky para esse campo de discussão, uma vez que o uso dessas atividades aumenta a capacidade de trabalho em grupo, promovendo maior interação social entre os estudantes.

De fato, uma aprendizagem só se configura como verdadeiramente significativa quando utilizada pelos docentes de forma que seja motivadora e desafiadora e, sobretudo, capaz de despertar nos educandos o interesse em buscar novos conhecimentos, em especial, os científicos.

\section{REFERÊNCIAS BIBLIOGRÁFICAS}

AMABIS, J. M. A premência da educação científica. WERTHEIN, J. CUNHA, C. (org.). Ensino de ciências e desenvolvimento. O que pensam os cientistas. 2. Ed. Brasília, UNESCO, Instituto Sangari, 2009, p. 155-160;

BOURDIER, Pierre, A escola conservadora: as desigualdades frente à escola e a cultura. In: Escritos de Educação, Petrópolis Vozes, 2006, p. 41-64.

DRUCK, S. educação científica no Brasil. Uma urgência. WERTHEIN, J. CUNHA, C. (org.). Ensino de ciências e desenvolvimento. O que pensam os cientistas. 2. Ed. Brasília, UNESCO, Instituto Sangari, 2009, p. 233-240;

FORÇA A. C.; LABURÚ C. E.; SILVA O. H. Atividades experimentais de física: teoria e prática. Disponível em http://www.nutes.ufrj.br/abrapec/viiienpec/resumos/R0035-1.pdf. Acesso em 11/04/20106;

KRASILCHIK, M. Ensino de ciências: um ponto de partida para a inclusão. WERTHEIN, J. CUNHA, C. (org.). Ensino de ciências e desenvolvimento. O que pensam os cientistas. 2. Ed. Brasília, UNESCO, Instituto Sangari, 2009, p. 207-211;

LABURAÚ, C. E. Seleção de experimentos de física no ensino médio: uma investigação a partir da fala dos professores. Investigação em Ensino de Ciências, v. 10, n. 2, 2005;

PAVAN, C. Investimento, Ciência e Educação. WERTHEIN, J. CUNHA, C. (org.). Ensino de ciências e desenvolvimento. O que pensam os cientistas. 2. Ed. Brasília, UNESCO, Instituto Sangari, 2009, p. 103-110;

PESSOA DE CARVALHO, A. M. introduzindo os alunos do universo das ciências. In: In: WERTHEIN, J. CUNHA, C. (org.). Ensino de ciências e desenvolvimento. $\mathbf{O}$ que pensam os cientistas. 2. Ed. Brasília, UNESCO, Instituto Sangari, 2009, p. 71-77;

PRAIA, J.; GIL-PEREZ, D.; VILCHES, A. O papel da natureza da ciência na educação para a cidadania. Ciência \& Educação, v. 13, n. 02, p. 141-156, 2007;

SANTOS, Júlio Cesar Furtado. Aprendizagem significativa - modalidades de aprendizagem e o papel do professor. Porto Alegre: editora mediação, 2008;

SILVA, L. H. de A.; ZANON, L. B. A experimentação no ensino de ciências. In: SCHNETZLER, R. O.; ARAGÃO, R. M. D. de (Org). Ensino de Ciências: fundamentos e abordagens. Campinas: UNIMEP, 2000. P. 120-153. 
TEDESCO, J. C. Formação científica para todos. In: WERTHEIN, J. CUNHA, C. (org.). Ensino de ciências e desenvolvimento. O que pensam os cientistas. 2. Ed. Brasília, UNESCO, Instituto Sangari, 2009, p. 161-171;

WERTHEIN, J. CUNHA, C. (org.). Ensino de ciências e desenvolvimento. O que pensam os cientistas. 2. Ed. Brasília, UNESCO, Instituto Sangari, 2009, p. 15-55;

VALÉRIO, M. BAZZO, W.A. O papel da divulgação científica em nossa sociedade de risco: em prol de uma nova ordem de relações entre ciência, tecnologia e sociedade. Revista Iberoamericana de Ciência, Tecnologia, sociedade e Innovación. nº. 7, Setembro-Dezembro 2006.

VYGOTSKY, L. S. A construção do pensamento e da linguagem. São Paulo. Editora Martins Fontes, 2001. 